\title{
Controlled blasting for safe excavation of a portion of irrigation canal in close vicinity of a village
}

\author{
Avtar K Raina and Pankaj Wankhede \\ CSIR-Central Institute of Mining \& Fuel Research, \\ Nagpur, India \\ rainaji@cimfr.res.in
}

\author{
PK Singh \\ CSIR-Central Institute of Mining \& Fuel Research, \\ Dhanbad, India
}

\begin{abstract}
A canal was proposed to be excavated by blasting nearby a village with hutments and an overhead water tank in very proximity. The structures mentioned were as near as $18 \mathrm{~m}$ from the proposed excavation. Trial blasts were conducted by CSIR-CIMFR to ascertain the vibration attenuation parameters and based on the studies a controlled blast design was recommended. This included use of estimated charge per delay and recommended blast design while using non-electrical initiation system and taking advantage of decoupled charges. The blasting over a length of around $100 \mathrm{~m}$ was thus excavated without any damage to the nearby structures. A total flyrock control was observed and attained in the entire excavation by using blast mats. The study describes the methods adopted and results obtained during the excavation.
\end{abstract}

Keywords-controlled blasting; irrigation canal; blast design; flyrock control; vibration control

\section{INTRODUCTION}

The Pench Diversion Project Right Bank Canal is being excavated by M.P. Irrigation Department through private agencies. The width and depth of the planned canal are $10 \mathrm{~m}$ and $5 \mathrm{~m}$, respectively. The main excavation method is drilling and blasting wherever the canal passes through hard rock. The canal is aligned about a village in Chindwara district with a diagonal distance ranging between 18 to $30 \mathrm{~m}$ from the canal edge towards the village. Structures like single story houses of different nature ranging from mud to cement mortar exist at the proposed site of the canal about the said village. The depth of excavation of the canal near the village was between 8 to $12 \mathrm{~m}$ from the surface. Hard rock could be visually seen outcropping along the alignment. This necessitated drilling and blasting method of rock breaking.

However, as mentioned kutcha houses were located very near to the blasting area (Fig. 1). An old cement concrete water tank exists at $13 \mathrm{~m}$ from the proposed canal (Fig. 2) but was $18 \mathrm{~m}$ from the nearest blast site. The contractor of the canal works awarded the assignment for suggesting controlled blasting to CSIR-CIMFR to ensure smooth excavation by controlled blasting to protect nearby structures from damage due to blasting and flyrock.

Controlled blasting is an established method but requires site specific inputs and characterization of the nature of ground vibrations, air overpressure. Flyrock remains a big issue in such conditions. The problem was critical as hutments were very near to the blasting site. This required a meticulous effort to design, implement and monitor blasting process during the excavation.

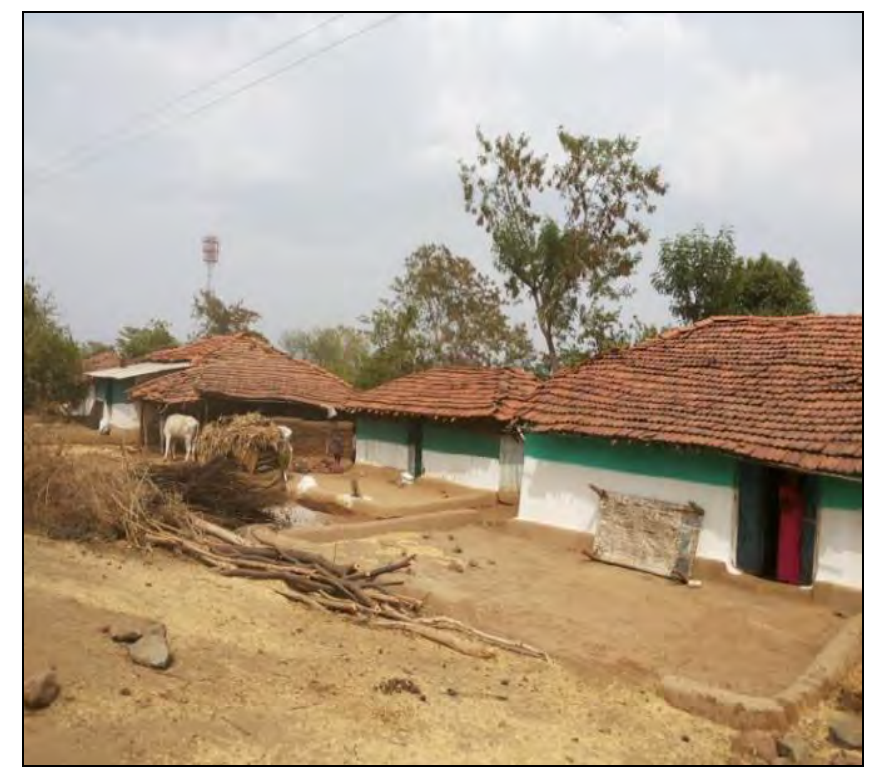

Fig. 1. Nature of structures near the proposed canal

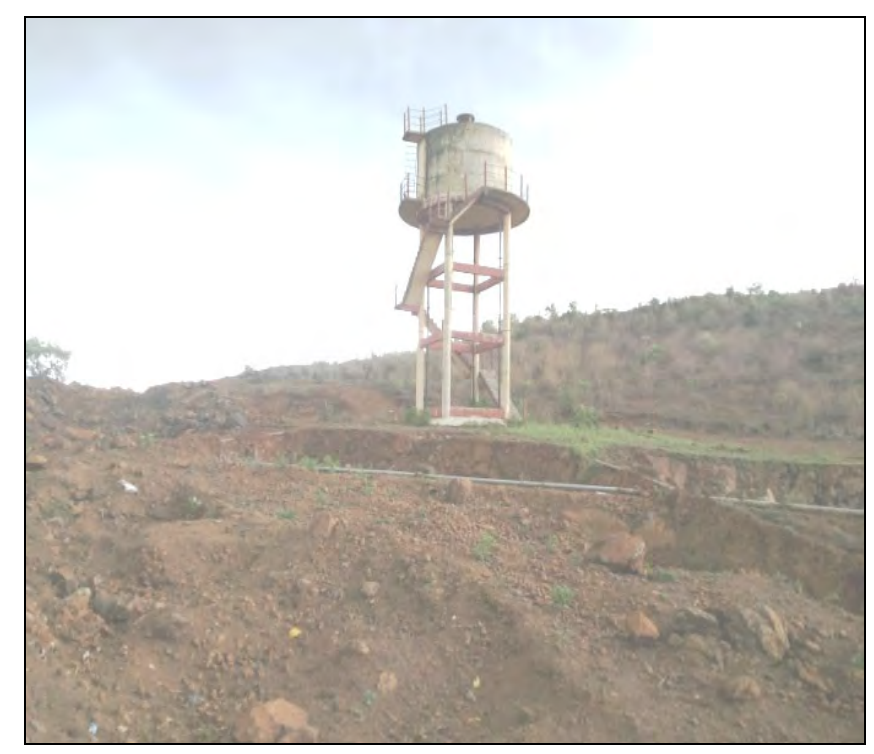

Fig. 2. View of the overhead water tank 


\section{Methodology}

\section{A. Initial Assessment}

CSIR-CIMFR adopted a comprehensive strategy to facilitate the excavation of the canal about the village. The method involved:

a) Physical inspection of the all the area.

b) Assessment of condition of all the houses around the excavation.

c) Assessment of condition of the overhead water tank.

d)Measurement of exact distances of structures from the proposed canal.

\section{B. Detailed Investigations}

The type of houses and any cracks whether superficial of deep in these were recorded and photographed. The strengths of the concrete of the overhead water tank and rock were estimated with the help of Schmidt hammer (Fig. 3 and 4).

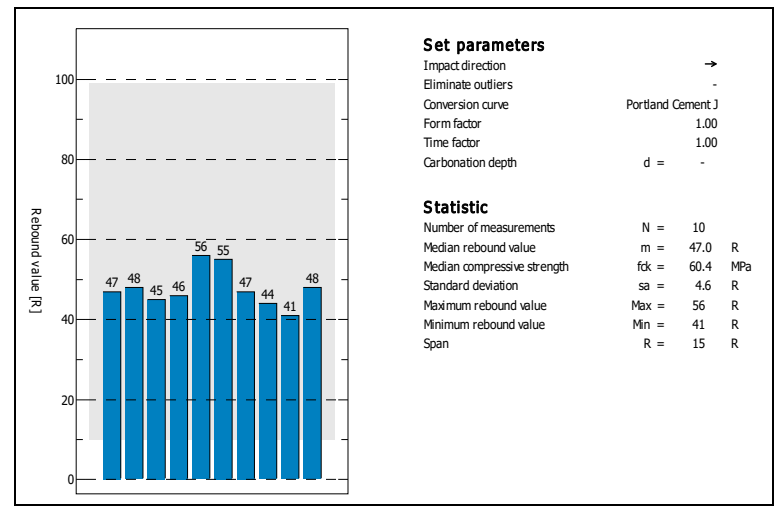

Fig. 3. Schmidt rebound test data of the overhead water tank concrete

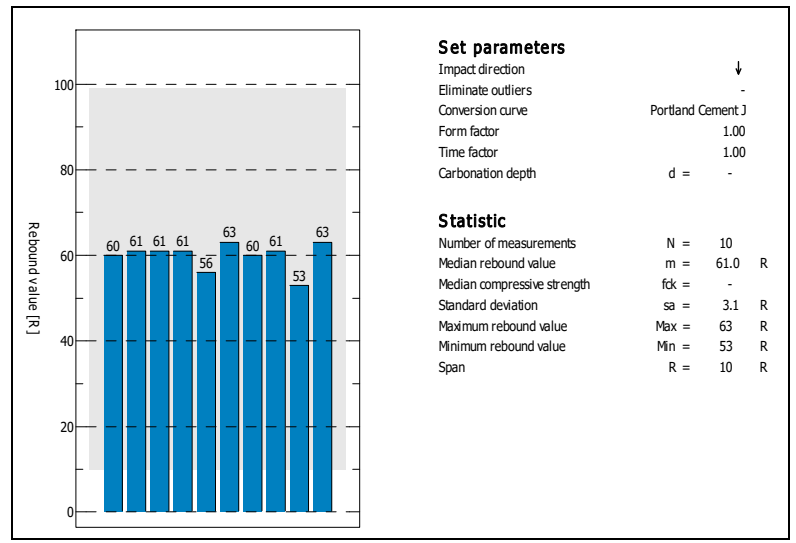

Fig. 4. Schmidt rebound test data of the in situ rock mass

The Schmidt data thus obtained showed that the overhead tank was having good quality concrete despite of several surficial crack. The rockmass to be blasted also emerged to be of very high strength. Based on the above data analysis of ground vibrations was conducted for determination of its attenuation parameters which worked out to be

$$
\mathrm{K}=1065 \& \alpha=1.55
$$

The values of the above parameters were further used to define maximum charge per delay for actual blasting for different distance from the blast sites. The recommended values are thus given in Table II.

Blast design was proposed based on the above analysis. The analysis predicted that the specific charge had to be maintained at a critical level in order to break the rock without crossing the stipulated limits of the ground vibrations.

The basic pattern worked out to be $2.0 \mathrm{~m} \times 3.0 \mathrm{~m}$ burden and spacing and a depth of $4 \mathrm{~m}$ or more. Since the charge per hole recommended was quite less in comparison to the blasthole diameter, this meant using decoupled charges so that the charge could be distributed. This helped also in containing the vibrations within the limits. In order to ensure the maximum charge per delay non-electrical detonators with shock tubes were suggested and used in the actual blasts. One of the designs thus recommended is thus shown in Fig. 6.

Table II was used to determine the charge per delay to be used while blasting. The blast design was evaluated with the help of BD2MAS (Blast Design and Database Management Application System, devised by CSIR-CIMFR). An example of determination of cooperating charges with the software is shown in Fig. 5

\section{TEST BLASTS AND ANALYSIS}

To design a controlled blasting strategy, it was essential to determine the attenuation characteristics of the ground vibrations induced by the blasting. The data for such analysis was generated by conducted test blasts. An initial estimate of the blast design variables was made based on the experience and published data in similar formations. The tests were conducted at not less than $30 \mathrm{~m}$ from the villages to ensure no damage to the structures during the trials. Simulations were made to ensure that vibrations do not exceed stipulated limits. In addition, muffling of the blasts was done in order to arrest any flyrock emanating from the trials blasts. The data thus generated is presented in Table I.

TABLE I: TRIAL BLAST DATA [1]

\begin{tabular}{|c|c|c|c|c|c|c|c|}
\hline $\begin{array}{c}\text { Blast } \\
\text { No. }\end{array}$ & $\begin{array}{c}\boldsymbol{R}_{\text {seis }} \\
\boldsymbol{m}\end{array}$ & $\begin{array}{c}Q_{\max } \\
\mathbf{k g}\end{array}$ & $\begin{array}{l}V_{\max } \\
\mathrm{mm} / \mathrm{s}\end{array}$ & $\begin{array}{c}f \\
H z\end{array}$ & $\begin{array}{l}P_{o a} \\
d B L\end{array}$ & $\begin{array}{l}R, \\
m\end{array}$ & $\begin{array}{r}R f \\
m\end{array}$ \\
\hline 1 & 40 & 8.0 & 26.2 & 15 & 124 & 4 & $\mathrm{Nil}^{\# 1}$ \\
\hline 1 & 63 & 8.0 & 6.9 & 17 & 117.6 & 4 & Nil \\
\hline 2 & 30 & 5.6 & 20.8 & 58.0 & 128.0 & 3 & Nil \\
\hline 2 & 32 & 5.6 & 13.8 & 28 & 122.0 & 3 & Nil \\
\hline 2 & 51 & 5.6 & $<1.0$ & 39 & 124 & 3 & Nil \\
\hline 3 & 54 & 5.1 & $<1.0$ & 45 & 126.0 & 2.5 & Nil \\
\hline 4 & 54 & 4.1 & 7.6 & 41.0 & 116.9 & 2.0 & Nil \\
\hline $\begin{array}{l}\text { LegeI } \\
R_{\text {seis }} \text { is } \\
Q_{\text {max }} \text { i } \\
V_{\text {max }} \text { is } \\
f \text { is do } \\
P_{\text {oa }} \text { is } \\
R \text { is } \mathrm{T}\end{array}$ & $\begin{array}{l}\text { stance } \\
\text { laxim } \\
\text { bratior } \\
\text { nant } f 1 \\
\text { over } \\
\text { ow of } 1\end{array}$ & $\begin{array}{l}\text { seism } \\
\text { charge } \\
\text { eak pa } \\
\text { uency } \\
\text { sure d } \\
\text { ken ro }\end{array}$ & $\begin{array}{l}\text { h from } \\
\text { delay, } \\
\text { veloci } \\
\text { bration }\end{array}$ & $\begin{array}{l}\text { st site, } \\
\mathrm{nm} / \mathrm{s} \\
\mathrm{z}\end{array}$ & . & & \\
\hline
\end{tabular}


TABle II. Predicted Maximum Charge Per Delay Based on Trial BLASTS

\begin{tabular}{|c|c|}
\hline $\begin{array}{c}\text { Distance of structure from blast } \\
\mathbf{~ m}\end{array}$ & $\begin{array}{c}\text { Maximum charge per } \\
\text { delay } \\
\mathbf{~ K g}\end{array}$ \\
\hline 18 & 1.3 \\
\hline 20 & 1.6 \\
\hline 22 & 2.0 \\
\hline 24 & 2.4 \\
\hline 26 & 2.8 \\
\hline 30 & 3.7 \\
\hline
\end{tabular}

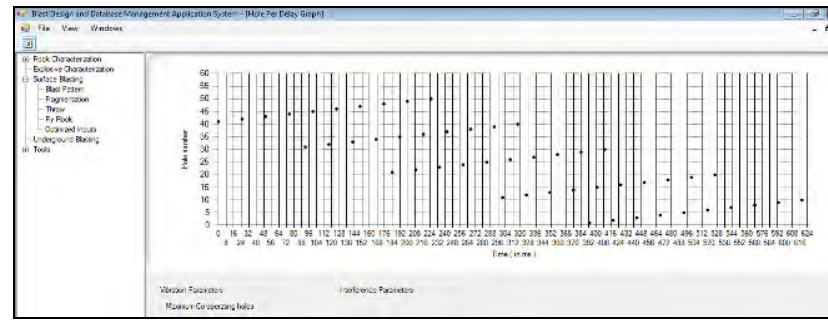

Fig. 5. Determination of delay overlap/cooperative holes with BD2MAS

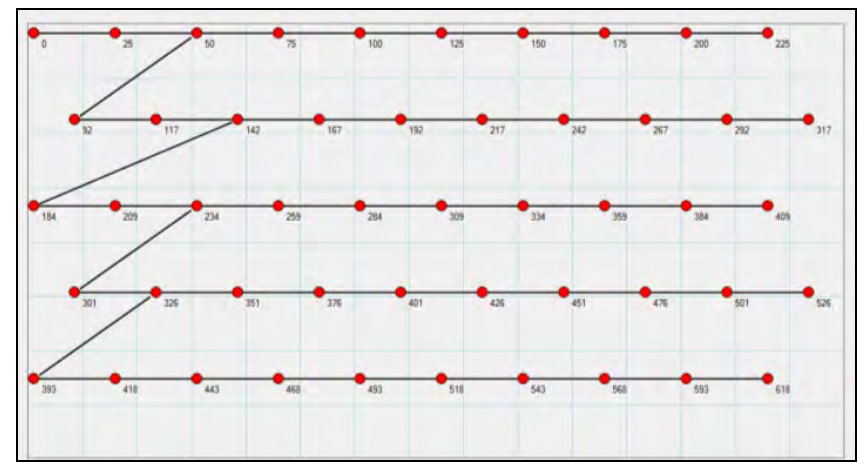

Fig. 6. Typical firing pattern used at the site

The blasting was carried over the entire stretch of the canal with the said blast design and ground vibrations were monitored. At places, since depth of the working was more than $10 \mathrm{~m}$, the excavation had to be done in more than one bench as the charge per hole was restricted.

\section{FLYROCK CONTROL}

Total flyrock control was observed during the entire excavation of the canal passing near the village. This was ensured by using a 2-tier mechanism of muffling (Fig. 7).

This involved the following procedure:

i) Charging of the blastholes as per the recommended method.

ii) Connecting the surface connectors as per the design.

iii) Covering the connectors with sandbags.

iv) Covering the entire blast area with a layer of sandbags.

v) Laying blast-mats over the layer of sandbags.

Images of actual blasting at the above said site are provided in Fig. 8(a-d).

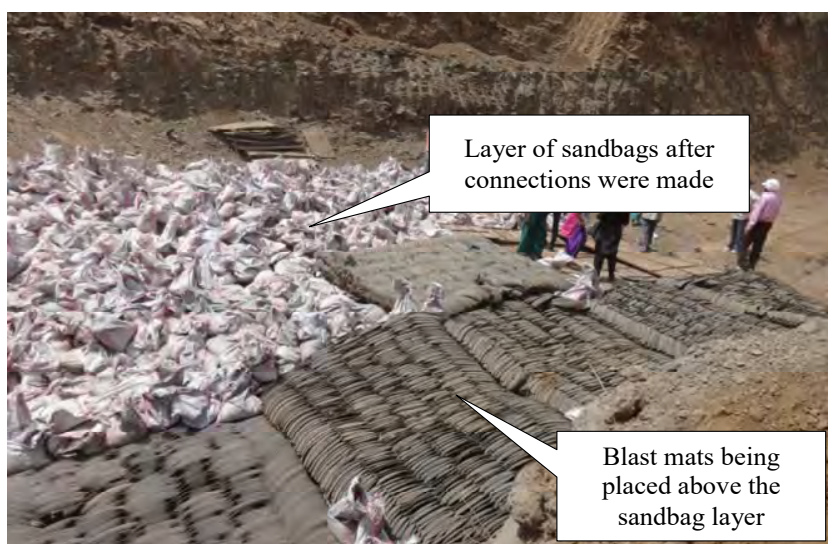

Fig. 7. Muffling arrangements for the blast
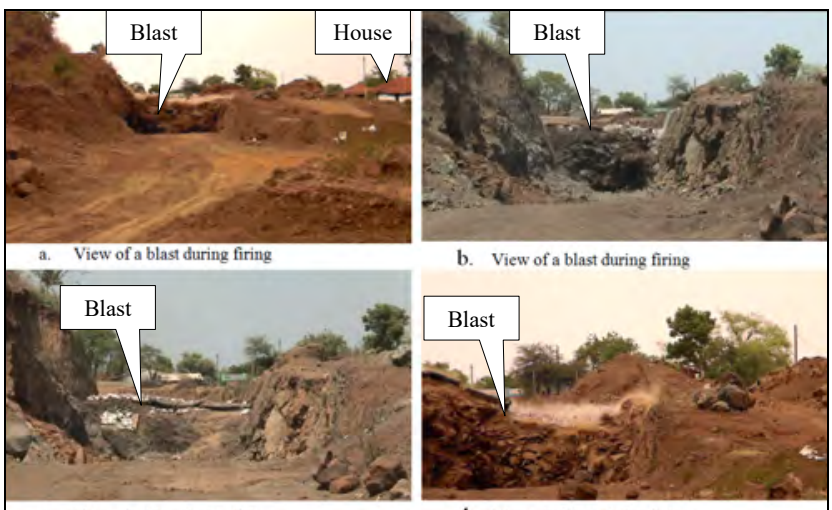

b. View of a blast during firing

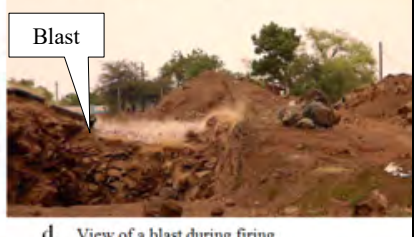

Fig. 8. View of different blasting during firing

In this manner, a total flyrock control was observed during the entire excavation process. No damage to the nearby structures or harm to any personnel residing in the village was reported during the entire excavation.

\section{COnClusions}

The controlled blasting strategy evolved for excavation of a canal very near to a village involved detailed planning and execution of the works. The damage to the nearby structures due to blasting was eliminated by restricting the charge per delay as per the attenuation equation devised for the said area. The charging in highly decoupled holes with minimum specific charge ensured both vibration control and breakage. Post blast inspection of the nearby structures revealed no enhancement of the existing cracks or generation of new cracks. There was no injury or damage due to flyrock as the flyrock was controlled fully with the help of multiple layers of muffling including blast-mats.

\section{ACKNOWLEDGEMENT}

Authors are thankful to the sponsoring agency for the award of the study.

\section{REFERENCES}

[1] CIMFR Technical Reports (unpublished), 2010-2016 